\title{
Pengukur Kecepatan Kendaraan Menggunakan Algoritma Image Subtracting
}

\author{
Fadlan Raka Satura ${ }^{1}$, Alfan Adi Chandra², Faisal Dharma Adhinata ${ }^{3, *}$ \\ 1,2,3 Program Studi Rekayasa Perangkat Lunak, Institut Teknologi Telkom Purwokerto, Indonesia \\ Email: ${ }^{1} 19104072 @$ ittelkom-pwt.ac.id, ${ }^{2} 19104026 @$ ittelkom-pwt.ac.id, ${ }^{3, *}$ faisal@ittelkom-pwt.ac.id \\ *) faisal@ittelkom-pwt.ac.id
}

\begin{abstract}
Abstrak- Pengendara di jalan raya dengan kecepatan yang tinggi mampu memicu kecelakaan lalu lintas yang akan mengakibatkan tabrakan antara pengendara lain. Pada alat pengukur kecepatan ini dapat meminimalisir terjadinya kecelakan di jalan raya, yang akan meningkatkan kedisiplinan dalam lalu lintas. Sistem perhitungan kecepatan ini menggunakan metode Image Subtracting dan metode Gaussian Mixture Model (GMM) untuk mendeteksi objek yang bergerak. Kemudian dilakukan perhitungan menggunakan garis pendeteksi objek dari awal bergerak pada garis pertama sampai dengan garis kedua. Dari informasi tersebut didapatkan kecepatan suatu kendaraan.
\end{abstract}

Kata Kunci: Kendaraan, Kecepatan, Image Subtracting, Gaussian Mixture Model, Pengendara

Abstract- Drivers on the highway at high speeds can trigger traffic accidents that will result in collisions between other drivers. This speed meter can minimize the occurrence of accidents on the highway, which will increase discipline in traffic. This speed calculation system uses the Image Subtracting method and the Gaussian Mixture Model (GMM) method to detect moving objects. Then the calculation is carried out using the object detection line from the beginning of moving on the first line to the second line. From this information obtained the speed of a vehicle.

Keywords: Vehicle, speed, Image Subtracting, Gaussian Mixture Model, Driver

\section{PENDAHULUAN}

Pengendara memiliki tingkat resiko kecelakaan yang tinggi, adapun penyebabnya pada transportasi darat adalah laju kendaraan yang tinggi. Kecepatan dalam berkendara mempunyai resiko yang cukup tinggi yang akan mengakibatkan tabrakan di jalan raya.[1]

Pembatasan kecepatan pada kendaraan baik di tol maupun di jalan raya sudah diterapkan pada Undang undang No. 22 tahun tahun 2009 tentang Lalu Lintas dan Angkutan Jalan. Pembatasan kecepatan yang di terapkan pada jalan raya memiliki berbagai macam factor yang diperhitungkan melalui penetapan batas kecepatan. Secara umum batas kecepatan terbagi atas 4 kawasan yakni di jalan tol minimal 60 km/jam dengan maksimal 100 km/jam, jalan antar kota maksimal kecepatan 70 km/jam, kawasan perkotaan maksimal kecepatan 50 km/jam, dan kawasan permukiman maksimal kecepatan $20 \mathrm{~km} / \mathrm{jam}$.

Pada Perkembangan teknologi yang semakin cepat yang pada umumnya terdapat CCTV dan kita dapat mengidentifikasi kendaraan tersebut, dengan ini petugas dapat dengan mudah melakukan pengawasan dan penindakan pelanggaran lalu lintas di jalan raya. Untuk alat yang dibutuhkan guna mendeteksi kecepatan kendaraan antara lain: Mikrokontroler dan kamera yang berbasis personal Komputer [2]. sensor yang digunakan untuk mendeteksi kecepatan diukur dengan berdasarkan jarak awal waktu hingga waktu tempuh yang sudah ditentukan. Jika terdapat kendaraan yang melanggar melebihi batas yang sudah ditentukan maka akan di capture menggunakan webcam yang akan terlihat plat mobil yang dikendarainya.

Pada system yang digunakan untuk pengukuran kecepatan kendaraan berbasis opencv Metode yang digunakan dalam sistem untuk mengukur kecepatan kendaraan berbasis OpenCV adalah dengan metode Gaussian Mixture Model [3]. Berguna untuk memisahkan foreground dengan latarbelakang, untuk memaksimalkan pendeteksian maka pada kamera / webcam akan diletakan $90^{\circ}$ dari kendaraan yang akan dideteksi.

Hal ini berguna untuk mengurangi resiko kecelakaan karena kecepatan yang cukup tinggi, maka dari itu kita dapat memanfaatkan kemajuan teknologi dalam segi berlalulintas dan juga dapat mengurangi pengawasan oleh pihak polisi secara langsung. Jadi, rumusan masalah yang diperoleh yakni bagaimana cara merancang sebuah sistem pendeteksi dan perhitungan kecepatan pada kendaraan menggunakan metode Image Subtracting serta menangkap gambar ketika kendaraan melebihi kecepatan maksimal. Adapun tujuan dari pembuatan jurnal ini yakni merancang sistem pengukur kecepatan kendaraan menggunakan metode Image Subtracting, berdasarkan peraturan yang berlaku Pada masyarakat umum guna meningkatkan budaya tertib lalu lintas dan mengurangi resiko kecelakaan saat berkendara. 


\section{METODE PENELITIAN}

Metode penelitian yang digunakan untuk mendeteksi kecepatan kendaraan adalah metode image subtracting untuk mendeteksi gerakan objek dengan warna pada video

\subsection{Alat dan Bahan}

Penelitian ini menggunakan bahan video yang menangkap objek kendaraan yang melintas. Kemudian penelitian ini menggunakan Perangkat Personal Komputer dengan Processor Intel Core i5 Gen 9 dan Memory 16 Gb untuk menjalankan Program mendeteksi kecepatan kendaraan dari video yang telah disediakan.

\subsection{Perancangan Sistem}

\subsubsection{Deskripsi Sistem}

Perancangan sistem ini dibuat berupa perangat lunak untuk pengolahan video. Video yang digunakan yaitu pada jalanan yang dilewati kendaraan yang melintas. Awal dari proses sistem ini yakni dimulai dengan memasukkan sebuah video yang akan diolah oleh sistem processing citra. Kemudian, sistem mendeteksi kendaraan dengan menggunakan metode image subtracting. Metode ini membutuhkan paling sedikit 2 frame untuk memisahkan latar belakang dengan layar depan. Selain itu, adapun cara lain yang dapat digunakan dengan memisahkannya dengan mencari perbedaan diantara kedua frame citra tersebut [4].

Apabila objek yang dituju terdeteksi, maka akan ditracking melalui titik pengukuran. Lalu dihitung pada koordinat awal dan akhir. Setelah menentukan koordinat awal dan akhir, tahap selanjutnya jarak akan dihitung. Sedangkan, untuk perhitungan waktu yang ditempuh dapat diketahui melalui selisih waktu saat melewati garis awal dan akhir.

Kecepatan pada kendaraan yang melaju didapatkan hasil pembagian antara jarak bagi dengan waktu tempuh. Sebelum melakukan percobaan maka akan dilakukan kalibrasi terlebih dahulu agar didapatkan kecepatan dengan satuan $\mathrm{km} / \mathrm{jam}$, agar didapatkan data yang tepat [5].

Dalam naskah, nomor kutipan secara berurutan dalam tanda kurung siku [3], juga tabel angka dan angka secara berurutan seperti yang ditunjukkan pada Tabel 1 dan Gambar 1.

\subsubsection{Perancangan Flowchart Algoritma}

Perancangan ini dilakukan untuk mempermudah alur penulisan program. Flowchart berisi tentang laju aliran suatu sistem yang akan dibuat [4]. Gambar 1 menunjukkan tahapan sistem pengukur kecepatan kendaraan.

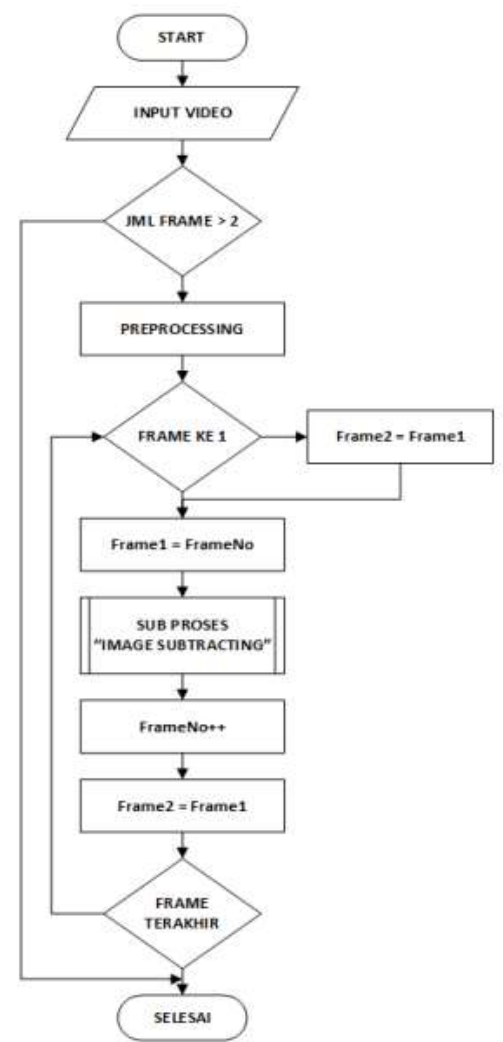

Gambar 1. Flowchart sistem 


\subsubsection{Perancangan Proses}

Perancangan ini digunakan dalam proses pengolahan data untuk mendapatkan hasil kecepatan kendaraan bergerak. Kecepatan kendaraan diperoleh dari perhitungan total jarak yang ditempuh dari awal objek sampai dengan akhir objek bergerak. Total jarak diperoleh dengan menggunakan bantuan garis awal dan akhir untuk mendeteksi objek ketika melewati garis [6].

$$
\text { Kecepatan Kendaraan }=\frac{\text { jarak } x \text { frames per second }}{\text { jumlah frame tempuh }}
$$

\section{HASIL DAN PEMBAHASAN}

\subsection{Deteksi Kendaraan}

Pada tahap ini akan dilakukan perubahan citra menggunakan metode image subtracting dimana video akan diubah citra video menjadi hitam putih untuk menemukan benda bergerak pada video, kemudian setelah perubahan citra sudah selesai dilakukan langkah selanjutnya adalah memberikan kotak atau Bounding Box pada objek yang telah terdeteksi.

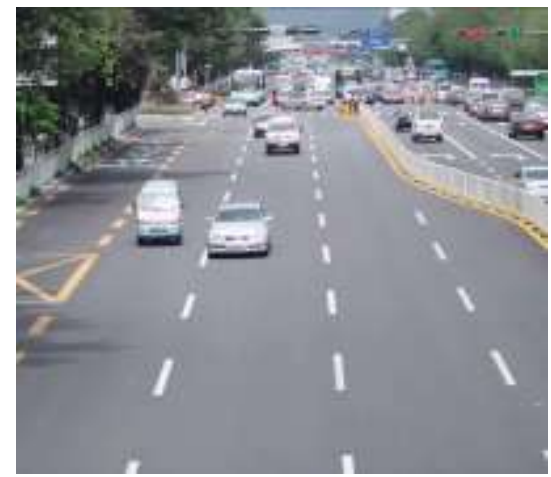

Gambar 2. Citra Asli video

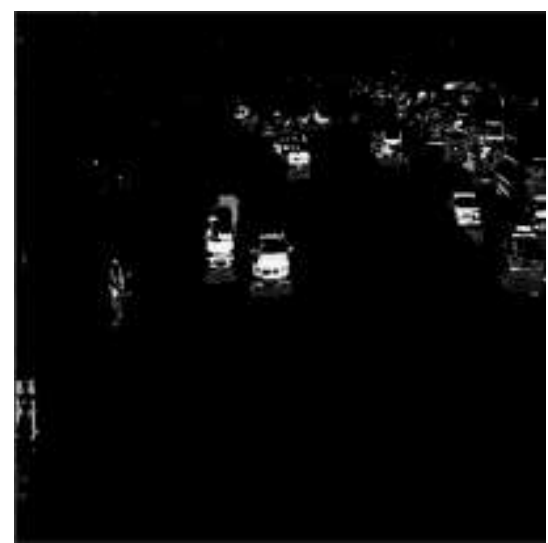

Gambar 3. Citra video setelah image subtracting

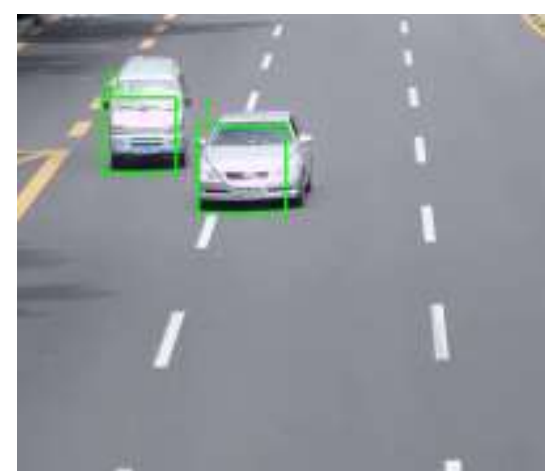

Gambar 4. Citra Video setelah Bounding Box 


\subsection{Deteksi Kecepatan}

Pada tahap deteksi kecepatan kendaraan ini akan dilakukan perhitungan kecepatan pada kendaraan dengan cara membuat 2 garis, dimana 2 garis tersebut adalah untuk menentukan total jarak yang ditempuh oleh objek yang bergerak dari garis pertama sampai dengan garis yang kedua.

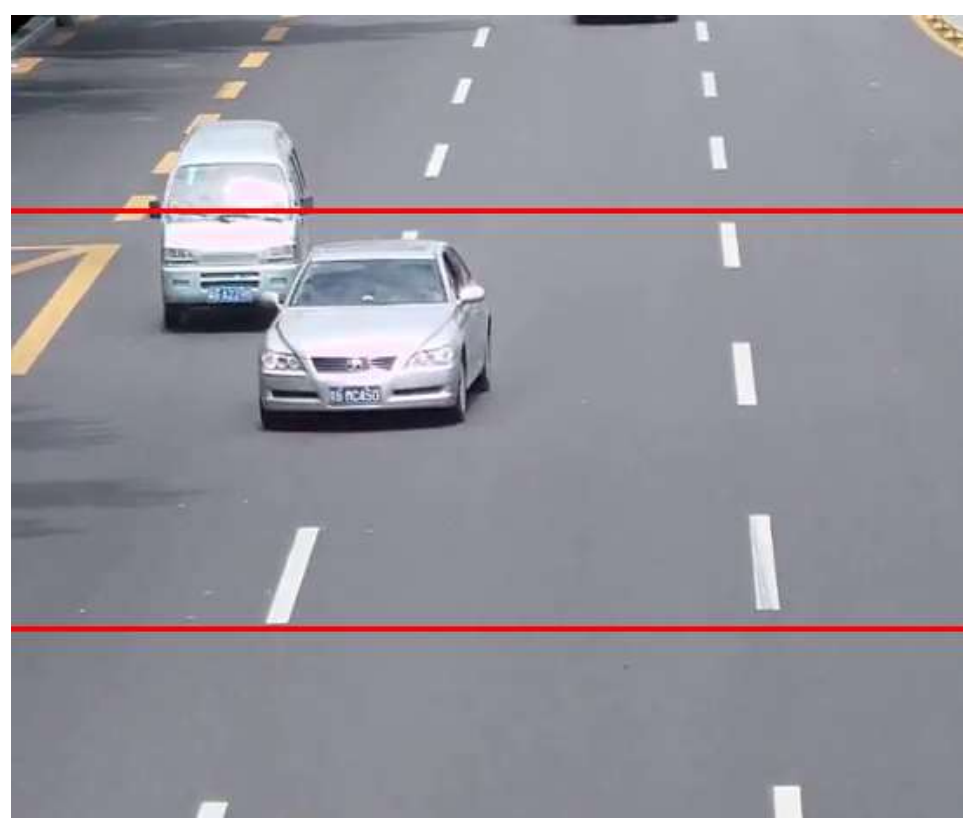

Gambar 5. Citra 2 Garis Pendeteksi

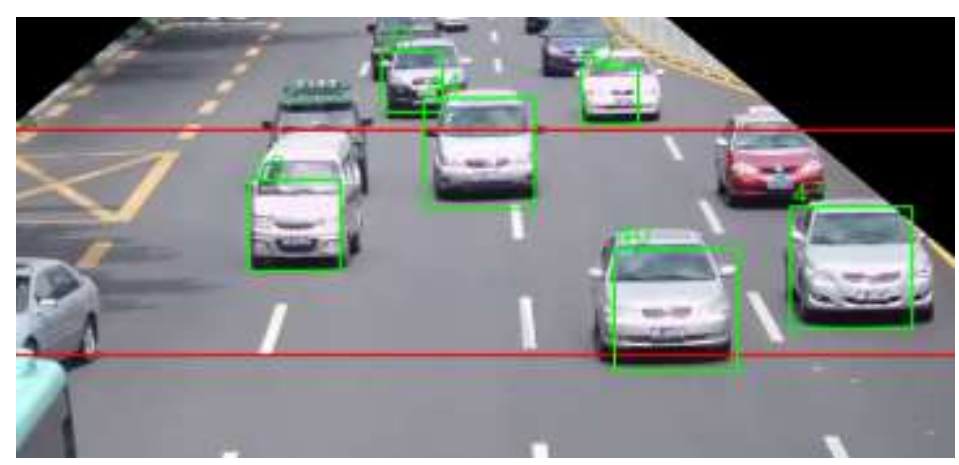

Gambar 6. Citra Bounding Box dan 2 Garis Pendeteksi

\subsection{Data Kecepatan}

Tahap ini dilakukan untuk melihat hasil dari pengujian deteksi kecepatan kendaraan dalam $\mathrm{km} / \mathrm{jam}$ pada video yang telah disediakan dan mengambil 10 data pertama.

\begin{tabular}{|c|c|c|c|}
\hline \multicolumn{4}{|c|}{ Tabel 1. Data Kecepatan Pertama } \\
\hline No & CAR-ID & Speed & Ket \\
\hline 1 & 1 & 42.28 & \\
\hline 2 & 0 & 24.94 & \\
\hline 3 & 2 & 59.43 & Overspeed \\
\hline 4 & 3 & 43.21 & \\
\hline 5 & 4 & 27.99 & \\
\hline 6 & 5 & 43.37 & \\
\hline 7 & 6 & 38.42 & \\
\hline 8 & 10 & 40.24 & \\
\hline 9 & 9 & 33.81 & \\
\hline 10 & 11 & 20.88 & \\
\hline
\end{tabular}


Tabel 2. Data Kecepatan Kedua

\begin{tabular}{|c|c|c|c|}
\hline No & CAR-ID & Speed & Ket \\
\hline 1 & 1 & 42.59 & \\
\hline 2 & 0 & 24.9 & \\
\hline 3 & 2 & 61.53 & Overspeed \\
\hline 4 & 3 & 43.56 & \\
\hline 5 & 4 & 28.57 & \\
\hline 6 & 5 & 42.57 & \\
\hline 7 & 6 & 29.49 & \\
\hline 8 & 10 & 39.45 & \\
\hline 9 & 9 & 32.9 & \\
\hline 10 & 11 & 20.43 & \\
\hline
\end{tabular}

Dari Tabel diatas dapat dihitung rata-rata untuk mendapatkan nilai error, sehingga dapat digunakan sebagai koreksi.

Tabel 3. Data Perbandingan Nilai Error

\begin{tabular}{rllr}
\hline CAR-ID & $\begin{array}{l}\text { Data } \\
\text { Pertama }\end{array}$ & Data kedua & Nilai Error $(\%)$ \\
\hline 1 & 42,28 & 42,59 & $-0,73$ \\
0 & 24,94 & 24,90 & 0,16 \\
2 & 59,43 & 61,53 & $-3,53$ \\
3 & 43,21 & 43,56 & $-0,81$ \\
4 & 27,99 & 28,57 & $-2,07$ \\
5 & 43,37 & 42,57 & 1,84 \\
6 & 38,42 & 29,49 & 23,24 \\
10 & 40,24 & 39,45 & 1,96 \\
9 & 33,81 & 32,90 & 2,69 \\
11 & 20,88 & 20,43 & 2,16 \\
\hline
\end{tabular}

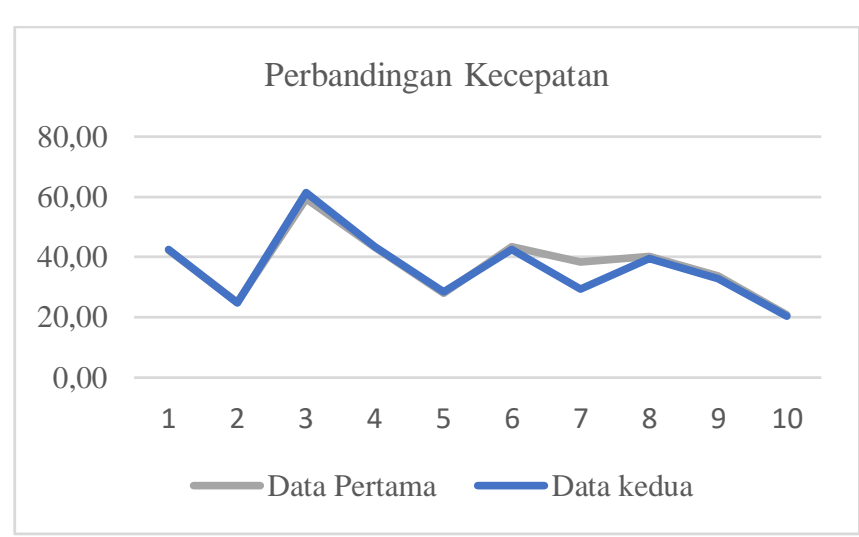

Gambar 7. Grafik Data Perbandingan

\subsection{Data kendaraan yang melebihi kecepatan}

Pada Tahap ini, kendaraan yang melebihi kecepatan maksimal yaitu $50 \mathrm{~km} / \mathrm{jam}$, maka sistem akan menyimpan data kendaraan berdasarkan Bounding Box kendaraan tersebut. 


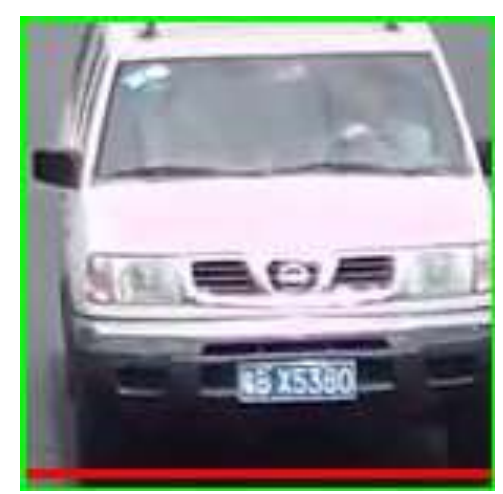

Gambar 8. Citra Bounding Box kendaraan ketika melebihi batas kecepatan

\section{Kesimpulan}

Dari hasil penelitian dan pengujian dapat ditarik kesimpulan bahwa Penggunaan image subtracting dapat melakukan pendeteksian objek dengan baik dan dengan metode ini sistem dapat melakukan pengukuran kecepatan kendaraan. kemudian apabila kecepatan kendaraan melebihi batas kecepatan maksimal yaitu $50 \mathrm{~km} / \mathrm{jam}$, maka gambar dari kendaraan tersebut akan tersimpan pada penyimpanan personal komputer, serta manfaat yang didapatkan yaitu kita dapat meminimalisir kecelakaan lalu lintas yang berada dijalan raya dan meningkatkan tata tertib berlalu lintas. Penelitian ini perlu disempurnakan untuk meningkatkan efektifitas serta pemanfaatan penggunaan vidio dan gambar dengan metode image subtracting mengingat yang digunakan dalam penelitian ini bersifat konseptual.

\section{DAFTAR PUSTAKA}

[1] H. Wartatmo, S. Kuschitawati, K. Kesehatan Pelabuhan Banten, U. Bedah Rumah Sakit Sardjito Yogyakarta, and D. Kesehatan Kota Yogyakarta, "Pengendara sebagai Faktor Risiko Terjadinya Kecelakaan Lalu Lintas Sepeda Motor Tahun 2010,”Ber. Kedokt. Masy., vol. 27, no. 2, p. 7, 2011.

[2] I. Setianingrum, "Alat Pendeteksi Kecepatan Kendaraan Bermotor Menggunakan Mikrokontoller Dan Webcam Berbasis Personal Computer,” J. Inform. Darmajaya, vol. 11, no. 2, pp. 28-33, 2011.

[3] S. S. Sadewo, R. Sumiharto, and I. Candradewi, "Sistem Pengukur Kecepatan Kendaraan Berbasis Pengolahan Video," IJEIS (Indonesian J. Electron. Instrum. Syst., vol. 5, no. 2, p. 177, 2015, doi: 10.22146/ijeis.7641.

[4] M. Kusuma Alfi Fauzi, Benny Firman, and Muhammad Andang Novianta, "PENGUKUR KECEPATAN KENDARAAN DI KAWASAN PEMUKIMANMENGGUNAKAN ALGORITMA IMAGE SUBTRACTING BERBASIS OPENCV,” J. Elektr., vol. 4, pp. 38-45, 2017.

[5] A. Andrew, J. L. Buliali, and A. Y. Wijaya, "Deteksi Kecepatan Kendaraan Berjalan di Jalan Menggunakan OpenCV," J. Tek. ITS, vol. 6, no. 2, pp. 366-371, 2017, doi: 10.12962/j23373539.v6i2.23489.

[6] I. Lugianti, J. Yusmah Sari, and I. Purwanti Ningrum, "Deteksi Kecepatan Kendaraan Bergerak Berbasis Video Menggunakan Metode Frame Difference,” Semin. Nas., vol. 1, pp. 324-332, 2012. 